\title{
Morphology of the larvae of Arrenurus nodosus Koenike, 1896; A. knauthei Koenike, 1895 and A. stecki Koenike, 1894 (Acari: Parasitengona: Arrenuridae)
}

\author{
A. Zawal \\ Department of Invertebrate Zoology \& Limnology. University of Szczecin, 71-415 Szczecin, Waska 13, Poland \\ E-mail : zawal@univ.szczecin.pl
}

\begin{abstract}
The morphology of the larval stages of Arrenurus nodosus, A. knauthei and A. stecki is described. Particular attention is paid to the different characters separating the three species. The larvae of the three species differ in the size and shape of the dorsal plate. Distinct differences appear between the proportions in the length of the lateral margins of the epimeres, which are similar in A. knauthei and A. stecki, but different in A. nodosus. There are differences in the shape of the excretory pore plates. In A. stecki the shape of the anal plate is slightly different owing to the truncated proleg. The structure of the pedipalps are very similar. The PIII1 setae are always bipectinate, the PIV1 is pectinate in A. knauthei and smooth in the other species, the PV6 is short and thick in A. nodosus, and long and thin in the other two species. Distinct differences also occur in the feathering of legs. The ITi8 seta is short in A. knauthei and long in the other two, the IITi10 seta is long in A. nodosus and short in the other two, and IIITi10 is thick and pectinate in A. nodosus, and smooth and fairly thin in the other two.
\end{abstract}

Keywords: Hydrachnidia, Arrenurus nodosus, A. knauthei, A. stecki, larvae, morphology.

\section{Introduction}

Because of the possibility of investigating relations between the larvae of water mites and their hosts, several scientists have currently been interested in the morphology of larval stages. Knowledge of these relationships can be useful in studying the distribution and dispersion of water mites and the mechanisms of evolution. The basic aim of such studies is to describe the morphology of the larvae of individual species. Larvae of the genus Arrenurus Duges are insufficiently known. Inadequate descriptions can be found in the works by Koenike (1908), Lundblad (1927, 1930), Miinchberg (1936) and Sparing (1959). The most detailed drawings and descriptions have been given by Imamura and Mitchell (1967), Prasad and Cook (1972), Vajnstejn (1980), Tuzovskij (1987), Smith (1990), Smith and Cook (1991) and Zawal (2006a, b, c, $d, e, f, g$ ).

The aim of this paper is to present detailed descriptions of A. nodosus, A. knauthei and A. stecki larvae in particular their differing features, and also to compare them with the earlier descriptions of other species of the genus Arrenurus.

\section{Material and Methods}

\section{Study area and field sampling}

The descriptions are based on larvae hatched from eggs laid by females caught in the field. Until egg laying, each female was kept in a separate $100 \mathrm{~cm}^{3}$ container filled with - water held at $20-24^{\circ} \mathrm{C}$ and subsequently fixed in Wilson's liquid. The eggs were kept, until hatching, under identical conditions. The larvae, $48 \mathrm{~h}$ post hatch, were mounted by embedding them in Hoyers medium; this time period was necessary for the larvae to became fully sclerotised.

Larval morphologies of Arrenurus nodosus, A. knauthei and A. stecki were described based on larvae hatched from eggs laid by a single female of each of the species, the females having been caught in speciesspecific habitats (a mid-forest pool among sedges, near Szczecin, Poland in the case of $\boldsymbol{A}$. nodosus collected on 18 June 1997; the lowland bog, near Goleniów, Poland among sedges in the case of $\boldsymbol{A}$. knnnuthei collected on 21 May 2003; the peat-bog, near Olsztyn, Poland among peatmoss in the case of $\boldsymbol{A}$. stecki collected on 28 May 2004). The mounts (A.nodosus: Nos 3R - female, 3Ra - larva; A. knauthei: Nos 894 - female, 894a larva; A. stecki: Nos 358E - female, and 358Ea - larva) are stored at the Department of Invertebrate Zoology and Limnology, University of Szczecin, 71-415 


\section{Szczecin. ul. Wàska 13.}

Larval body parts were measured on the progeny of two females of $A$. nodosus, one female of $A$. knauthei, and 10 females of $A$. stecki.

Drawings were prepared with a drawing attachment to a Nikon ECLIPSE80i microscope, all the details being carefully traced. It is very difficult to adequately represent the arrangement of the secondary setae as they are frequently hardly visible. For this reason, those setae bearing secondary ones were drawn as they were spotted, at least in one mount. Consequently, all the setae drawn appear to bear secondary setae, as they in fact do. On the other hand, the lack of secondary setae on smooth primary ones could have been caused by overlooking them on a mounted specimen.
The setal notation follows that of Prasad and Cook (1972) with modification by Zawal (2006a). The metriccharacters are reported with their ranges, mean values, and standard deviations. The leg segments were measured from their distal margins.

\section{Results}

\section{Morphology of Arrenurus nodosus}

The dorsal plate is oval-shaped, widest in the middle of its length. The anterior margin is almost straight and the posterior margin is widely rounded. The anteriorlateral indents are small with slightly obtuse angles, and reach to about one-quater of the olate width and one-seventh of its length. The Lpl seta is tripartite; the remaining setae are smooth (Fig. 1).

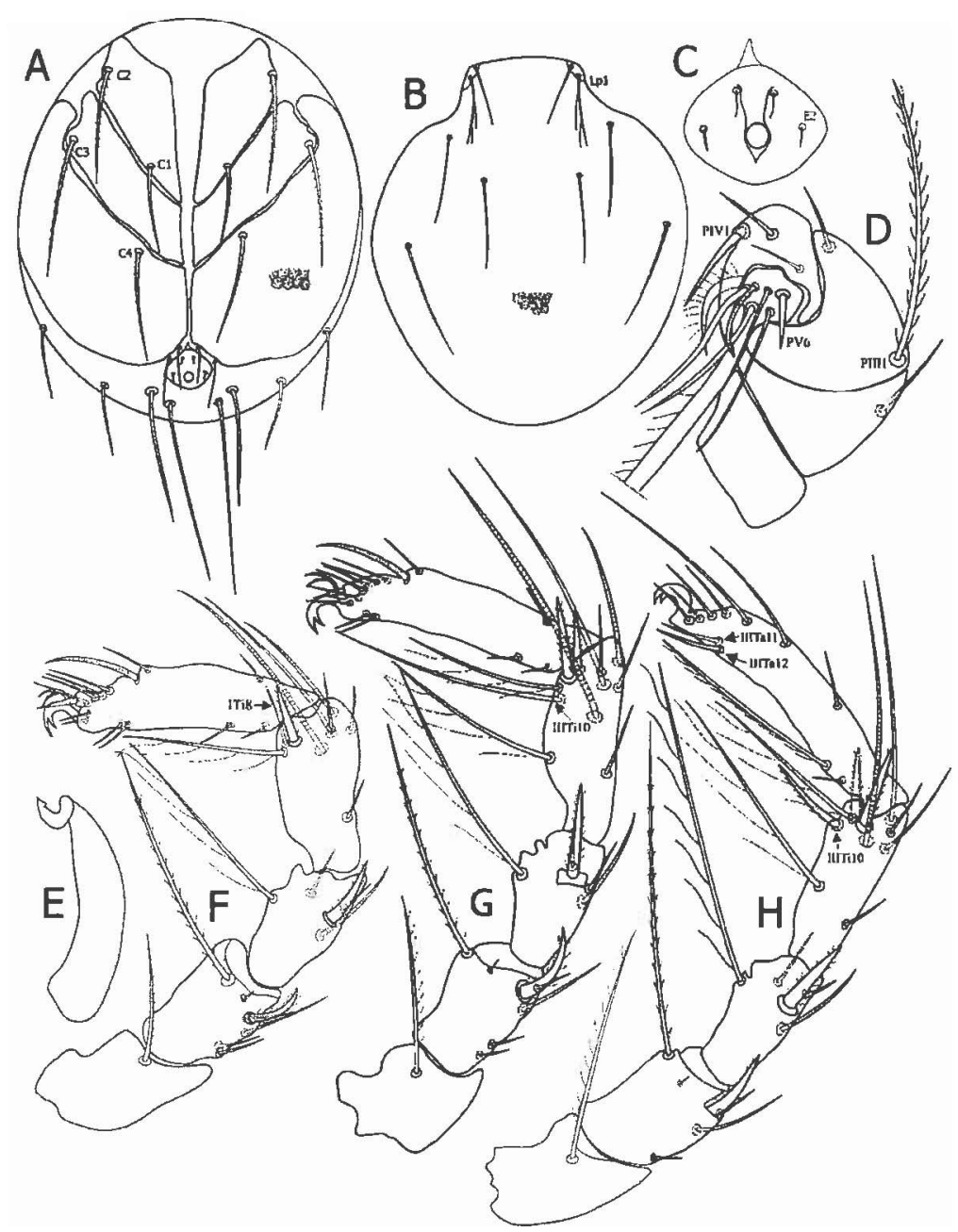

Fig. 1. Morphology of the larva of Arrenurus nodosus: A - ventral side, B -dorsal side, C -excretory pore plate, D - pedipalp, E - chelicera, F - leg I, $G$ - leg II, H - leg III (see text for explanations). 
Table 1. Dimensions ( $\mu$ un) of individual body parts

\begin{tabular}{|c|c|c|c|c|c|c|c|c|c|}
\hline & \multicolumn{3}{|c|}{ A. nodosus } & \multicolumn{3}{|c|}{ A. knauthei } & \multicolumn{3}{|c|}{ A. stecki } \\
\hline & range & mean & $\begin{array}{l}\text { standard } \\
\text { deviation }\end{array}$ & range & me & $\begin{array}{l}\text { standard } \\
\text { deviation }\end{array}$ & range & meal & $\begin{array}{l}\text { tandard } \\
\text { leviation }\end{array}$ \\
\hline length & $190-210$ & 197.8 & 5.37 & $260-318$ & 297.8 & 17.60 & $214-234$ & 222.4 & 6.65 \\
\hline width & $164-186$ & 5177.0 & 6.20 & $230-260$ & 243.4 & 9.05 & $198-206$ & 5202.4 & 3.24 \\
\hline dorsal plate length & $186-200$ & 193.0 & 4.55 & $260-302$ & 284.0 & 13.43 & $202-216$ & 6210.2 & 5.92 \\
\hline dorsal plate width & $148-168$ & 8157.0 & 6.41 & $228-240$ & 233.6 & 4.40 & $190-200$ & 195.0 & 3.56 \\
\hline CpI medial margin length & $63-67$ & 64.8 & 1.25 & $86-90$ & 87.4 & 1.13 & $72-82$ & 75.5 & 2.59 \\
\hline CpII medial margin length & $31-35$ & 33.3 & 1.14 & $41-46$ & 43.0 & 1.51 & $30-36$ & 33.7 & 1.62 \\
\hline CpIII medial margin length & $29-34$ & 31.4 & 1.30 & $54-60$ & 57.0 & 1.55 & $44-48$ & 45.5 & 1.10 \\
\hline distances: Mpl-Mpl & $44-48$ & 45.2 & 1.15 & $42-50$ & 44.5 & 2.39 & $41-46$ & 43.1 & 1.28 \\
\hline Lpl-Lpl & $50-58$ & 53.7 & 2.18 & $56-60$ & 57.4 & 1.35 & $49-56$ & 52.1 & 1.94 \\
\hline Lp2-Lp2 & $80-88$ & 83.4 & 2.50 & $90-103$ & 97.4 & 4.28 & $94-102$ & 98.6 & 2.26 \\
\hline Mp2-Mp2 & $45-50$ & 47.8 & 1.68 & $70-74$ & 72.4 & 1.08 & $50-54$ & 52.0 & 1.00 \\
\hline Mh1-Mp2 & $38-44$ & 40.7 & 1.86 & $58-69$ & 62.1 & 4.19 & $54-61$ & 58.2 & 1.99 \\
\hline Mpl-Lpl & $6-10$ & 7.7 & 1.32 & $8-11$ & 9.5 & 0.96 & $6-8$ & 7.2 & 0.65 \\
\hline MpI-Lp2 & $30-36$ & 33.1 & 1.52 & $36-40$ & 37.1 & 1.37 & $34-38$ & 36.2 & 1.00 \\
\hline Mp1-Mp2 & $58-61$ & 59.4 & 0.91 & $90-96$ & 93.2 & 2.42 & $64-69$ & 66.4 & 1.60 \\
\hline Mp2-Mhl & $22-30$ & 26.8 & 2.30 & $16-20$ & 17.6 & 1.36 & $29-38$ & 34.9 & 2.45 \\
\hline distance behveen $\mathrm{C} 1$ and $\mathrm{CpI}$ & $14-18$ & 15.9 & 0.88 & $22-26$ & 24.0 & 1.19 & $18-22$ & 19.7 & 1.01 \\
\hline distance between $\mathrm{C} 4$ and CpIII & $22-26$ & 24.1 & 1.43 & $35-38$ & 36.2 & 0.76 & $28-31$ & 29.6 & 1.07 \\
\hline distance between $\mathrm{C} 1$ and $\mathrm{C} 2$ & $50-56$ & 53.5 & 1.75 & $66-70$ & 68.5 & 1.20 & $42-46$ & 44.0 & 0.92 \\
\hline excretory pore plate length & $21-25$ & 22.6 & 1.25 & $40-44$ & 41.9 & 1.08 & $34-36$ & 35.0 & 0.93 \\
\hline excretory pore plate width & $23-27$ & 24.7 & 1.10 & $42-46$ & 43.3 & 1.16 & $36-42$ & 38.2 & 1.95 \\
\hline distance between Exp and Expp posterior margin & $6-10$ & 7.3 & 1.03 & $16-21$ & 18.3 & 1.43 & $8-13$ & 10.1 & 1.32 \\
\hline distance between El setae and Expp anterior margin & $4-6$ & 4.6 & 0.54 & $10-13$ & 10.5 & 2.51 & $12-14$ & 12.6 & 0.83 \\
\hline distance between E2 setae and Expp posterior margin & $8-11$ & 9.5 & 0.88 & $14-19$ & 17.0 & 1.31 & $12-14$ & 12.7 & 0.80 \\
\hline PI length & $8-10$ & 8.6 & 0.66 & $9-13$ & 10.5 & 1.22 & $8-12$ & 10.0 & 1.32 \\
\hline PII length & $22-26$ & 24.6 & 1.07 & $26-30$ & 29.2 & 1.65 & $26-30$ & 27.3 & 1.33 \\
\hline PIII length & $23-27$ & 25.2 & 1.21 & $26-30$ & 27.9 & 0.88 & $27-30$ & 28.7 & 0.96 \\
\hline length of PIV claw & $18-22$ & 19.4 & 1.12 & $24-28$ & 25.6 & 1.55 & $22-26$ & 24.2 & 1.00 \\
\hline length of cheliceral segment I & $78-84$ & 82.0 & 1.74 & $129-140$ & 134.8 & 2.90 & $81-84$ & 82.3 & 1.16 \\
\hline length of PV 8 seta & $150-231$ & 1161.3 & 24.91 & $202-210$ & 205.6 & 2.99 & $130-163$ & 3142.9 & 8.72 \\
\hline
\end{tabular}

The CpII and CpIII lateral margins are equal, and the $\mathrm{C}$ I lateral margin is twice as long. The $\mathrm{C} 2$ and $\mathrm{C} 3$ setae are bipectinate, and the $\mathrm{C} 1$ and $\mathrm{C} 4$ setae are pectinate (Fig. 1). The $\mathrm{C} 1$ and $\mathrm{C} 4$ setae are situated fairly near to the coxal plates lateral margins, and the distance between the $\mathrm{C} 1$ seta and the $\mathrm{CpI}$ lateral margin reach to about $2 / 3$ of the distance between $\mathrm{C} 4$ and CpIII lateral margin (Table 1).

The excretory pore plate is rhomboidal, its width slightly exceeds its length. The excretory pore is situated posterior to the centre of the plate and posterior of the E2 setae. The E1 setae are situated near to the Expp anterior margin (Table 1, Fig. 1).

The pedipalps are typical for the larvae of Arrenurus genus. The PIII1 is bipectinate, the PV6 seta is short and thick (Fig. 1).

The first segment of the chelicerae has the form of an elongated, clearly curved cylinder, strongly narrowed posteriorly (Fig. 1).

The proportions of the segments are more or less the same on each limb. The obviously shortest trochanter constitutes about $2 / 3$ rds of the length of the femur and genu which are of the same length; the tibia is 1.5 times longer and the tarsus twice as long (Table 2). The 
Table 2. Dimensions ( $\mu \mathrm{m})$ of leg segments

\begin{tabular}{|c|c|c|c|c|c|c|c|c|c|c|c|c|c|c|c|}
\hline & \multicolumn{3}{|c|}{ trochanter } & \multicolumn{3}{|c|}{ femur } & \multicolumn{3}{|c|}{ genu } & \multicolumn{3}{|c|}{ tibia } & \multicolumn{3}{|c|}{$\overline{\operatorname{tarsus}}$} \\
\hline & range & mean & $\begin{array}{l}\text { standard } \\
\text { deviation }\end{array}$ & range & mean & $\begin{array}{l}\text { standard } \\
\text { deviation }\end{array}$ & range & mean & $\begin{array}{l}\text { standard } \\
\text { deviation }\end{array}$ & range & mean & $\begin{array}{l}\text { Standard } \\
\text { deviation }\end{array}$ & range & mean & $\begin{array}{l}\text { standard } \\
\text { deviation }\end{array}$ \\
\hline 1 & $19-24$ & 20.9 & 1.48 & $30-35$ & 32.3 & 1.32 & $30-36$ & 31.6 & 1.82 & $38-43$ & 39.9 & 1.48 & $56-62$ & 58.9 & 1.97 \\
\hline 8ू II & $18-22$ & 19.7 & 0.86 & $30-34$ & 31.8 & 1.31 & $30-34$ & 31.4 & 1.25 & $42-46$ & 43.8 & 1.20 & $60-66$ & 62.2 & 1.59 \\
\hline सं III & $22-29$ & 26.0 & 2.48 & $30-34$ & 31.4 & 1.12 & $30-34$ & 31.7 & 1.26 & $42-48$ & 44.6 & 2.03 & $62-67$ & 63.8 & 1.50 \\
\hline$\tilde{\Xi}$ & $22-26$ & 25.0 & 1.13 & $42-45$ & 43.1 & 0.96 & $38-42$ & 40.6 & 1.18 & $53-56$ & 54.3 & 0.89 & $70-75$ & 72.3 & 1.42 \\
\hline 疍 II & $22-25$ & 23.4 & 0.85 & $40-46$ & 42.8 & 1.57 & $38-42$ & 40.2 & 1.05 & $57-61$ & 58.9 & 1.20 & $80-84$ & 82.1 & 1.20 \\
\hline$\nabla^{\prime}$ III & $22-26$ & 24.6 & 1.24 & $42-45$ & 43.6 & 1.02 & $39-42$ & 40.8 & 1.00 & $62-66$ & 63.9 & 0.88 & $82-88$ & 84.7 & 1.62 \\
\hline I & $22-26$ & 24.0 & 1.31 & $34-38$ & 34.9 & 1.20 & $33-35$ & 34.6 & 0.85 & $46-53$ & 50.8 & 2.30 & $66-67$ & 66.4 & 0.65 \\
\hline 党 II & $24-27$ & 26.0 & 1.26 & $34-39$ & 36.6 & 1.36 & $32-36$ & 34.9 & 1.32 & $46-50$ & 48.2 & 1.20 & $66-71$ & 68.4 & 1.57 \\
\hline III & $28-30$ & 28.9 & 0.96 & $36-38$ & 36.6 & 0.66 & $33-37$ & 35.1 & 1.33 & $43-48$ & 46.3 & 1.58 & $70-77$ & 73.6 & 1.92 \\
\hline
\end{tabular}

ITi8 is thin and fairly long. The IITi10 is very long, smooth and lies about one-third from the distal margin of the tibia; the IIITi10 is short, thick, pectinate and lies near to the distal margin of the tibia. The IIITa11 and IIITa12 setae are smooth, and the IIITa13 seta is pectinate (Fig. 1).

\section{Morphology of Arrenurus knauthei}

The dorsal plate is oval-shaped, widest in the middle of its length. The anterior margin is almost straight and the posterior margin is fairly widely rounded. The anterior-lateral indents are very small with slightly obtuse angles, and reach to about one-fifth of the plate width and one-seventh of its length. The Lpl seta is tripartite; the remaining setae are smooth (Fig. 2).

The lateral margins of the $\mathrm{CpI}$ are distinctly the longest, followed by $\mathrm{CpIII}$ and the shortest of lateral margin of $\mathrm{CpII}$ (Fig. 2). The ratio of $\mathrm{CpI} / \mathrm{CpII} / \mathrm{CpIII}$ are 21111.3 respectively (Table 1 ). The posterior-lateral margins of CpIII have fairly big indents where the cxcretory pore plate is situated. All the setae on the epimeres are pectinate. The distance between the $\mathrm{C} 1$ seta and the CpI lateral margin reach to about 213 of the distance between $\mathrm{C} 4$ and CpIII lateral margin. The distance between $\mathrm{C} 1$ and $\mathrm{C} 2$ setae are fairly long (Table 1). The excretory pore plate is oval-shaped, its width slightly exceeds its length. The excretory pore is situated slightly posterior to the centre of the plate and slightly anterior of the E2 setae. The E1 setae are situated fairly far from the Expp anterior margin (Table 1, Fig. 2).

The pedipalps are typical for the larvae of Arrenurus genus. The PIII1 is bipectinate, the PIV1 seta is fairly thin, long and pectinate; the PV6 and PV8 setae are long (Fig. 2).

The first segment of the chelicerae has the form of an elongated cylinder slightly narrowed posteriorly with one margin slighly depressed and another one sligtly convex (Fig. 2).

The proportions of segments are more or less the same on each limb. The obviously shortest trochanter constitutes about half of the length of the femur. The genu is slightly shorter then the femur; the tibia is 1.5 times longer and the tarsus twice as long (Table 2). The ITi8 is thin and fairly short, the IIGe3 and IIIGe3 setae are fairly thick and bipectinate. The IIITa11, IIITa12 and IIITa13 are pectinate, and the IITi10 and IIITi10 are smooth and situated about one-third from the distal end of the tibia (Fig. 2).

\section{Morphology of Arrenurus stecki}

The dorsal plate is oval-shaped, widest in the middle of its length. The anterior margin is almost straight and the posterior margin is fairly widely rounded. The anterior-lateral indents are are fairly big with slightly ob- 
tuse angles, and reach to about one-third of the plate width and one-fifth of its length. The Lpl seta is tripartite; the remaining setae are smooth (Fig. 3).

The lateral margins of the $\mathrm{CpI}$ are distinctly the longest, followed by CpIII and the shortest of lateral margin of $\mathrm{CpII}$ (Fig. 3). The ratio of $\mathrm{CpI} / \mathrm{CpII} / \mathrm{CpIII}$ are 2.2/1/1.4 respectively (Table 1 ). The posterior-lateral margins of CpIII have fairly big indents where the $\mathbf{c x}$ cretory pore plate is situated. All the setae on the epimeres are smooth (Fig. 3). The distance between the
C1 seta and the $\mathrm{CpI}$ lateral margin reach to about 213 of the distance between $\mathrm{C} 4$ and $\mathrm{CpIII}$ lateral margin. The distance between $\mathrm{C} 1$ and $\mathrm{C} 2$ setae are fairly small (Table 1).

The excretory pore plate is rhomboidal, its width slightly exceeds its length. The excretory pore is situated near the base of characteristic, pointed process, posterior to the centre of the plate and posterior of the E2 setae. The E1 setae are situated some distance from the Expp anterior margin (Table 1, Fig. 3).

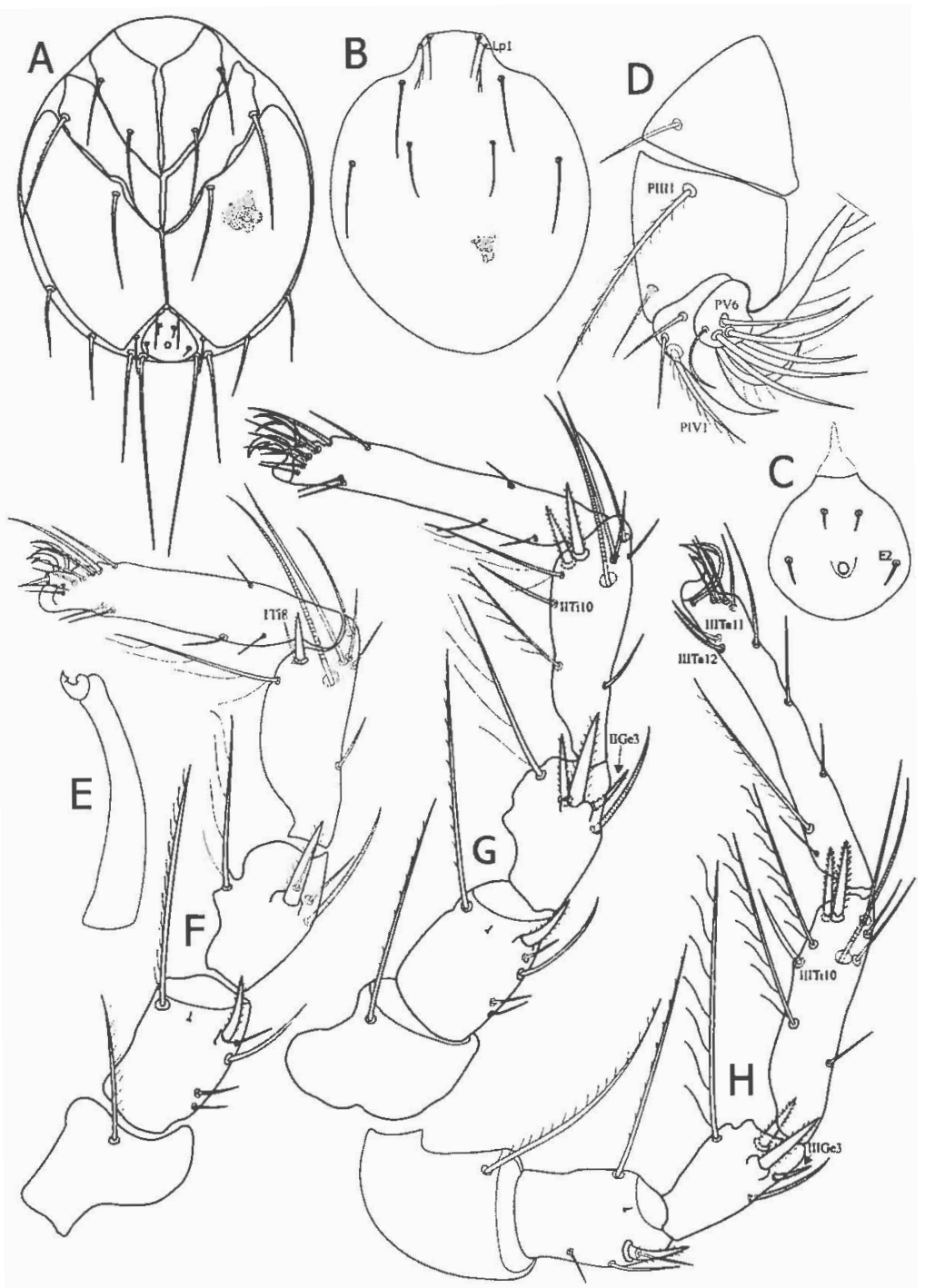

Fig. 2. Morphology of the larva of Arrenurus knauthci: A - ventral side, B - dorsal side, C - excretory pore plate, D - pedipalp, E - chelicera, F - leg I, G - leg II, H - leg III (see text). 


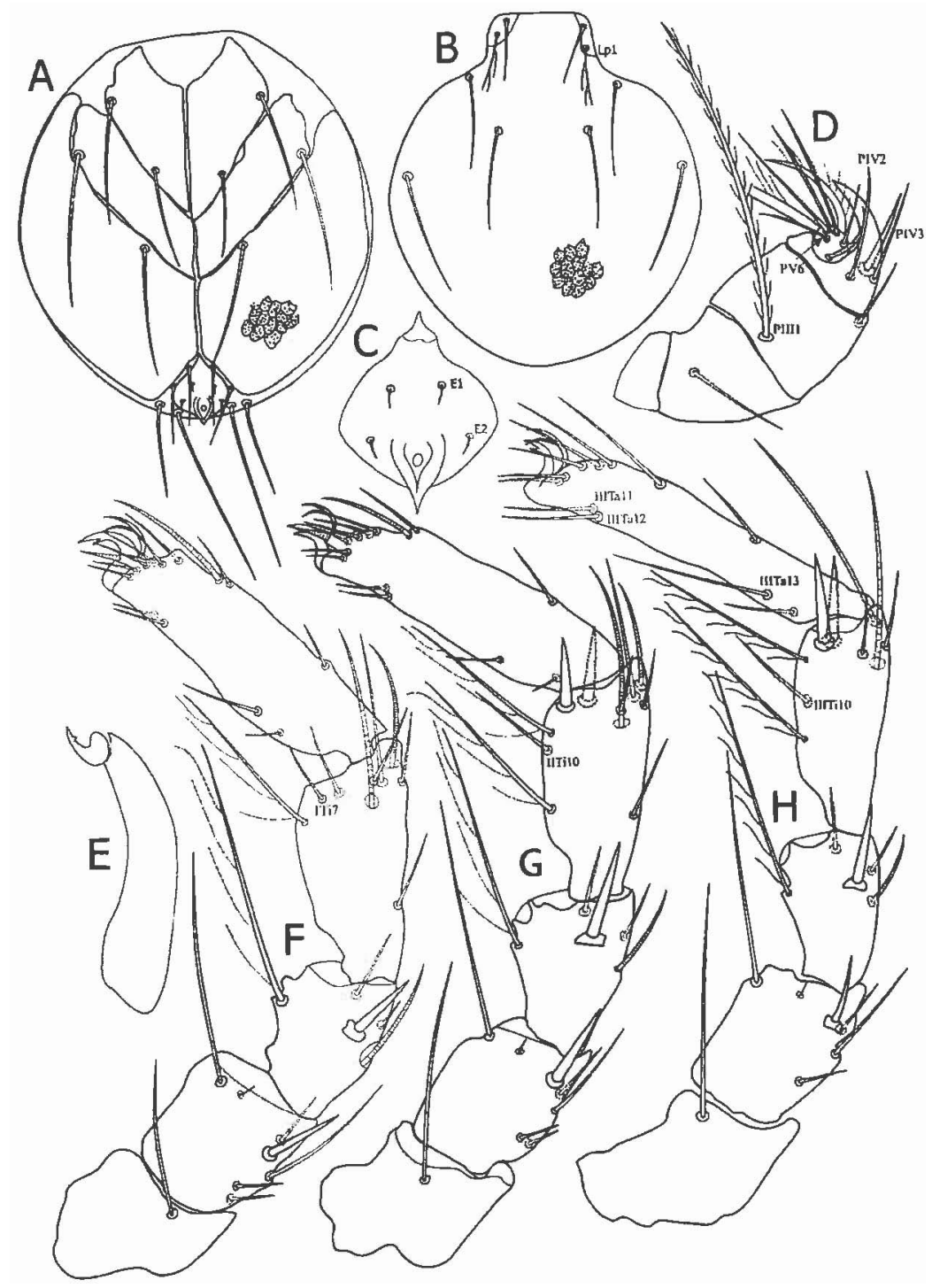

Fig. 3. Morphology of the larva of Arrenurus stecki: A - ventral side, B - dorsal side, C - excretory pore plate, D - pedipalp, E - chelicera, F leg I, $\boldsymbol{G}-$ leg II, H - leg III (see text).

The pedipalps are typical for the larvae of the genus Arrchurus. The PIII1 is bipectinate, the PV6 seta is fairly long; the PIV2 and PIV3 setae are fairly long; and the PV8 seta is fairly short (Fig. 3).

The first segment of the chelicerae has the form of an elongated, clearly curved cylinder, narrowed posteriorly (Fig. 3).

The proportions of segments are more or less the same on each limb. The obviously shortest trochanter constitutes about $2 / 3$ of the femur and genu which are of the same length; the tibia is 1.5 times longer and the tarsus twice as long (Table 2). The tarsi (particularly the II and III pair) are thick. The ITi7 is thin and fairly long. The IITi10 and IIITi10 setae are fairly thin, smooth and they are situated: IITi10 - about one-third from the distal end of the tibia; IIITi10 - about one-half from 
distal end of the tibia. The IIITa11, MITa12 and IIITa13 setae are smooth (Fig. 3).

\section{Discussion}

The larvae of the three species described differ in size and in the size of their dorsal plates. The largest is the larva of $\boldsymbol{A}$. knauthei, followed by $\boldsymbol{A}$. stecki and $\boldsymbol{A}$. nodosus (Table 1). All of them have oval-shaped, fairly wide dorsal plates, similar to A. papillator (Zawal $2006 \mathrm{~g}$ ), which differ in their larger anterior-lateral indents. The largest, similar to A. papillator, anterior-lateral indents are in the dorsal plate of $\boldsymbol{A}$. stecki, the smallest and the shortest anterior margin are in the dorsal plate of $\boldsymbol{A}$. knauthei and this is similar to A. crassicaudatus (Zawal 2006c). The anterior-lateral indents in A. nodosus are larger then in A. knautlzei and smaller then in $\boldsymbol{A}$. stecki, which is similar to A. mediorotundatus (Zawal 2006d). All of the three species described have widely rounded posteriorly dorsal plates, but the widest is in A. stecki, followed by A. nodosus and A. knauthei.

Differences in the length of the coxal plates are consequences of differences in the body size. However ratios in the length of the dorsal plates is the same in $\boldsymbol{A}$. knauthei and A. stecki (CpII is the shortes, followed by CpIII and CpI like in the most of Arrenurus species), and clearly different in A. nodosus (length of $\mathrm{CpII}$ and $\mathrm{CpIII}$ is equal, and CpIII is clearly longer which is similar to A. latus). The posterior-lateral margins of CpIII in A. knauthei and A. stecki have fairly big indents where the cxcretory pore plate is situated which is similar to A. cylindratus (Zawal 2006d). There are some differences in the appearance of the setae on the coxal plates: all of them in A, stecki are smooth; all of them in A. knauthei are pectinate; and the $\mathrm{C} 2, \mathrm{C} 3$ setae are bipectinate, and the $\mathrm{C} 1, \mathrm{C} 4$ setae are pectinate in $\boldsymbol{A}$. nodosus.

The excretory pore plate in $\boldsymbol{A}$. nodosus is rhomboidal like A. bruzelli (Zawal 2006b). The excretory pore plate in A. knauthei is oval-shaped like that of A. latus (Zawal 2006e), and the excretory pore plate in A. stec$\boldsymbol{k i}$ is intermediate in type between that of $\boldsymbol{A}$. knauthei and $\boldsymbol{A}$. stecki, and is closest to A. cylindratus (Zawal $2006 \mathrm{~d}$ ), but it has pointed process which is characteristic for only this species.

The pedipalps of the three species described are typical for the larvae of Arrenurus. They differ in the sizes of the PIV2, PIV3 and PV6 setae, and PIV1 pectinate in A. knauthei which is characteristic for only this species.
The shape of chelicerae of the three species are similar and they are like those in A. latus and A. bruzelli (Zawal 2006b), their sizes are almost equal in A. nodosus and A. stecki, and they are clearly larger in A. knauthei.

The tarsi of A. knautkei (particularly II and III pair) are clearly longer and thiner than the two other, and they are like the tarsi of A. bicuspidator (Zawal 2006f). The ITi8 in A. knauthei is clearly shorter than in the other species. The IITi10 and IIITi10 in A. knauthei and $A$. stecki are similar to each other and they are situated in the same places, but in A. nodosus the IITi10 is very long and in IIITi10 is short, pectinate and lies nearer to the distal end of the tibia than in both other species. The IIGe 3 and IIIGe 3 in A. knauthei is thicker than in both of the other species and pectinate, like in A. latus. The IIITa11 and IIITa12 setae in $\boldsymbol{A}$. knauthei are pectinate, and in A. nodosus and A. stec$k i$ are smooth. It should be pointed out that many of the secondary setae are difficult to see under the microscope, and are therefore not a good systematic character.

\section{Acknowledgement}

I thank E. Biesiadka for consultation and R. A. Baker for corrections to the text. Financial support was provided by Komitet Badan Naukowych in years 2004-2007, research grant no. 2P04C10527.

\section{References}

Imamura T. \& Mitchell R. 1967. - The water mites parasitic on the damseltly, Cercion hierglyphicum Brauer. $I$. Systematics and life history. Amnot. Zool. Japon., 40, 28-36.

Koenike F. 1908. - Beitrag zur Kenntnis der Hydrachniden. Abh. naturw. Ver., Bremen, 19, 245-250.

Lundblad O. 1927. - Die Hydracarinen Schwedens. I. Beitrag zur Systematik, Enibryologie, Okologie und Verbreitungsgeschichte der schwedischen. Arten. Zool. Bidrag, 11, 185-540.

Lundblad O. 1930. - Hydracarina. Zoology of the Furoes Copenhagen, 2, 1-65.

Münchberg P. 1936. - Zur Morphologie der Arrenurus- und Georgella-Larven nehst -Nymphen, mit besonderer Beriicksichtigung der Libellenparasiten. Arch. Naturg. N. F. 5, 93-1 15.

Prasad V. \& Cook. D.R. 1972. - The taxonomy of water mite larvie. Mem. Am. ent. Inst., 18, 1-326

Smith B.P. 1990. - Description of larval Arrenurus bartonensis Cook, Arrenurus hirgei Marshall, Arrenurus neobirgei Cook, and Arrenurus rotundus Marshall (Acari: Hydrachnidia; Arrenuridae) Cart. Ent. 122, 77-91.

Smith I.M. \& Cook D.R. 1991. - Water mites. Pages 523-592 in Ecology and Classification of North American Freshwater Invertebrates. Thorp J.H.\& Covich A.P. (eds). New York, Academic Press.

Sparing J. 1959. - Die Larven der Hydrachnellae, ihre parasitische Entwicklung und ihre Systematik. Parasit. Schr. rciche. 10, $1-168$.

Tuzovskij P.V. 1987. - Morphologia i postentbrionalnoie rnswitie wodianvch kliesciej. Nauka, Moscow, 172 p.

Vajnstejn B.A. 1980. - Opriedielitiel liāinok wodianych kliesciej. 
A. ZAWAL

Nauka, Leningrad, $238 \mathrm{p}$.

Zawal A. 2006a. - Morphology of larval stages of Arrenurus cuspidator (O. F. Müller, 1776), and A. maculator (O. F. Miiller. 1776) (Acari: Hydrachnidia). Zootaxa, 1194, 57-68.

Zawal A. 2006b. - Morphology of larval stages of Arrenurus albator (O. F. Müller, 1776), and A. fimbriatus Koenike, 1885 and A. bruzelli Koenike, 1885 (Acari: Hydrachnidia). Genus, 17, 141-150.

Zawal A. 2006c. - Morphology of larval stages of Arrenurus crassicaudatus Kramer, 1875; A. inexploratus Viets, 1930 i A. integra$\operatorname{tor}$ (0. F. Müller), 1776. Acarologia. (in press).

Zawal A. 2006d. - Morphology of larval stages of Arrenurus mediorotundatus Thor. 1898; A. conicus Piers 1894; and A. cylindratus Piers, 1896 (Acari: Hydrachnidia: Arrenuridae). Zool. Anz. (in press).

Zawal A. 2006e. - Morphology of Arrenurus cuspidifer Piersig. 1896; A. claviger Koenike, 1885; and A. latus Barrois \& Moniez,
1887 larvae (Acari: Parasitengona: Arrenuridae). Zoornxa. (in press).

Zawal A. 2006t. - Morphology of the larval stages of Arrenurus bicuspidator Berlese, 1885; A. tricuspidator (0.F. Miiller, 1776) and A. tetracyphus Piersig, 1894. Acarina. (in press).

Zawal A. 2006g. - Morphology of larval stages of Arrenurus papillator (O. F. Miiller, 1776), and A. pustulator (O.F. Miiller, 1776) (Acari: Hydrachnidia). Genus. (in press). 